\title{
Conformational modulation of sequence recognition in synthetic macromolecules
}

Article

Accepted Version

Zhu, Z., Cardin, C., Gan, Y., Murray, C. A., White, A. J. P., Williams, D. J. and Colquhoun, H. M. (2011) Conformational modulation of sequence recognition in synthetic macromolecules. Journal of the American Chemical Society, 133 (48). pp. 19442-19447. ISSN 0002-7863 doi: https://doi.org/10.1021/ja2067115 Available at https://centaur.reading.ac.uk/25448/

It is advisable to refer to the publisher's version if you intend to cite from the work. See Guidance on citing.

Published version at: http://pubs.acs.org/doi/abs/10.1021/ja2067115

To link to this article DOI: http://dx.doi.org/10.1021/ja2067115

Publisher: American Chemical Society

All outputs in CentAUR are protected by Intellectual Property Rights law, including copyright law. Copyright and IPR is retained by the creators or other copyright holders. Terms and conditions for use of this material are defined in the End User Agreement.

\section{www.reading.ac.uk/centaur}

\section{CentAUR}


Central Archive at the University of Reading

Reading's research outputs online 


\title{
Conformational Modulation of Sequence Recognition in
}

\section{Synthetic Macromolecules}

\author{
Zhixue Zhu, ${ }^{* \dagger}$ Christine J. Cardin,${ }^{\dagger}$ Yu Gan,${ }^{\dagger}$ Claire A. Murray, ${ }^{\dagger}$ Andrew J. P. White, ${ }^{*}$ David J. Williams ${ }^{\star}$ and \\ Howard M. Colquhoun*t \\ †Department of Chemistry, University of Reading. Whiteknights, Reading, RG6 6AD, UK; \\ * Chemical Crystallography Laboratory, Department of Chemistry, Imperial College, London, SW7 2AY, UK
}

Email: h.m.colquhoun@rdg.ac.uk; zhixue.zhu.rdg@googlemail.com

\section{RECEIVED DATE:}

TITLE RUNNING HEAD: Conformational Modulation of Sequence-Recognition

\begin{abstract}
The different triplet sequences in high molecular weight aromatic copolyimides comprising pyromellitimide units ("I") flanked by either ether-ketone ("K") or ether-sulfone residues ("S") show different binding strengths for pyrene-based tweezer-molecules. Such molecules bind primarily to the diimide unit through complementary $\pi-\pi$-stacking and hydrogen bonding. However, as shown by the magnitudes of ${ }^{1} \mathrm{H}$ NMR complexation shifts and tweezer-polymer binding constants, the triplet "SIS" binds tweezer-molecules more strongly than "KIS" which in turn bind such molecules more strongly than "KIK". Computational models for tweezer-polymer binding, together with single-crystal X-ray analyses of tweezer-complexes with macrocyclic ether-imides, reveal that the variations in binding strength between the different triplet sequences arise from the different conformational preferences of aromatic rings at diarylketone and diarylsulfone linkages. These preferences determine whether or not chain-folding and secondary $\pi-\pi$-stacking occurs between the arms of the tweezermolecule and the 4,4'-biphenylene units which flank the central diimide residue.
\end{abstract}




\section{Introduction}

Some of the most fundamental mechanisms of molecular biology - notably replication, transcription and translation of nucleic acids - depend on supramolecular recognition of monomer sequence-information in linear copolymers. ${ }^{1,2}$ There is no reason, in principle, why such recognition processes should not also be accessible in synthetic copolymer systems. However, despite tremendous advances in supramolecular and polymer chemistry in recent decades, work on the recognition of sequence-information in high molar mass copolymers has remained focused largely on bio-macromolecules. ${ }^{3}$ Some related work with synthetic copolymers has been described however, including site-specific polyrotaxane formation, ${ }^{4}$ and "self-sorting" whereby different small-molecule receptors bind to different complementary side-groups on a copolymer chain. ${ }^{5,6}$ It has also been shown that specific imide-centered triplet sequences in linear aromatic copolyimides can be bound with high selectivity by electron-rich "tweezer molecules", 7,8 Sequence-recognition by such tweezer-molecules depends on complementary $\pi-\pi$ stacking interactions, ${ }^{9}$ polymer chain-folding, ${ }^{10}$ and hydrogen bonding of amide groups, present in the tweezer-molecule, to the pyromellitimide units. ${ }^{7,11,12,13}$ Two different approaches to sequence-selective binding have been described in these systems, based either on the introduction of sterically-hindered environments around some of the pyromellitimide units, ${ }^{7}$ or the use of co-monomers such as 4,4'(hexafluoroisopropylidene)diphthalic anhydride which introduce specifically non-binding diimide residues into the copolymer chain. ${ }^{12}$

In the present paper we describe a new and more subtle expression of sequence-information in synthetic copolymer systems, whereby the conformational preferences of groups adjacent to the pyromellitimide residue modulate, but do not eliminate, the binding capability of diimide-centered triplet sequences. It is known that the lowest-energy conformation of a diarylsulfone residue corresponds to an "open book" geometry, with the aromatic rings normal to the C-S-C plane (Figure 1a), ${ }^{14,15}$ whereas diarylketone groups prefer a "twisted" conformation, with a range of twist angles, generally averaging ca. $\pm 30^{\circ}$, relative to the bridging C-C-C unit (Figure 1b). ${ }^{14,16}$ 
(a)

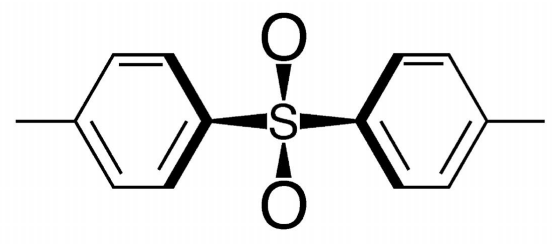

\section{(b)}

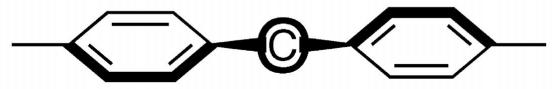

Figure 1. Representations of the conformational energy-minima for diarylsulfone and diarylketone residues: torsion angles (a) C-C-S-C $\approx 90^{\circ}$, (b) C-C-C(O)-C $\approx \pm 30^{\circ} . .^{14}$

A consequence of the preferred "open-book" conformation at the diarylsulfone unit is that macrocylic ether-imide-sulfones such as $\mathbf{1}$ and $\mathbf{2}$ (Chart 1) have internal cavities flanked by parallel, electron-poor diimide and 4,4'-biphenylenedisulfone residues, lying perpendicular to the mean ring-plane and separated by ca. $8 \AA .^{17,18}$ This "parallel-wall" geometry (Figure 2, at right) enables the macrocyclic imide-sulfone to act as a strongly-binding receptor for planar, electron-rich aromatic substrates such as pyrene and perylene and their derivatives, via multiple, complementary $\pi$ - $\pi$-stacking. ${ }^{17,18}$ Extrapolation of these binding characteristics to homologous poly(imide-sulfone)s led to our discovery of tripletsequence recognition by tweezer-molecules,., ${ }^{71,12,13}$ Given the "twisted" ground state conformation of the diarylketone unit, ${ }^{14,16}$ it seemed possible that triplet sequences comprising diimide residues flanked by diarylketone groups would be a poorer fit to tweezer-molecules such as $\mathbf{3}$ and $\mathbf{4}$, and so have different binding characteristics from those of sulfone-based systems. This idea is confirmed in the present paper, through studies of tweezer-binding to both macrocyclic and polymeric ether-imide systems.

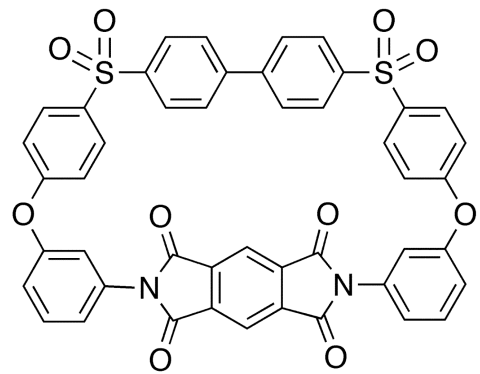

1

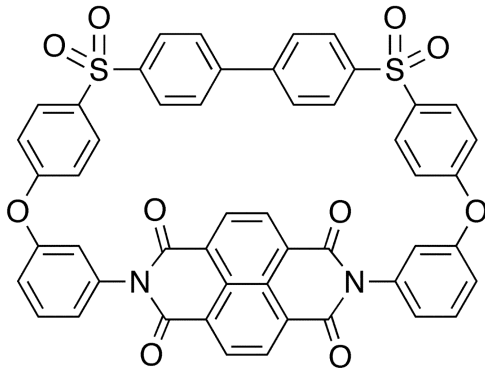

2

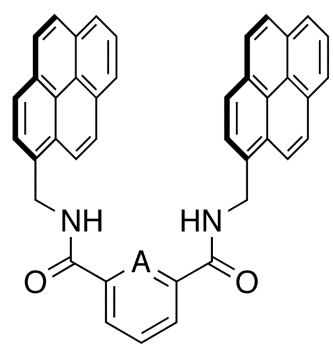

$3(\mathrm{~A}=\mathrm{CH}), \mathbf{4}(\mathrm{A}=\mathrm{N})$

Chart 1. Macrocyclic ether-imide-sulfones $\mathbf{1}$ and $\mathbf{2},{ }^{18}$ and tweezer-molecules $\mathbf{3}$ and $\mathbf{4}$. $^{7}$ 


\section{Results and Discussion}

Cyclo-condensation of the ether-ketone-diamine $\mathbf{5}$ with pyromellitic dianhydride and with naphthalene1,4,5,8-tetracarboxylic dianhydride, under pseudo-high dilution conditions, afforded the novel macrocycles 6 and 7 respectively (Scheme 1), albeit in very low yields $(<2 \%)$. Such yields contrast with the corresponding syntheses of the sulfone-based macrocycles $\mathbf{1}$ and $\mathbf{2}$ (Chart 1), for which yields of $>20 \%$ are reported, ${ }^{18}$ suggesting that the preferred torsion angle at the ketone linkage (C-C-C-C $\approx$ $\left.30^{\circ}\right)^{14,16}$ makes ring-closure less facile than the corresponding angle at sulfone $\left(\mathrm{C}-\mathrm{C}-\mathrm{S}-\mathrm{C} \approx 90^{\circ}\right) .^{14,15}$
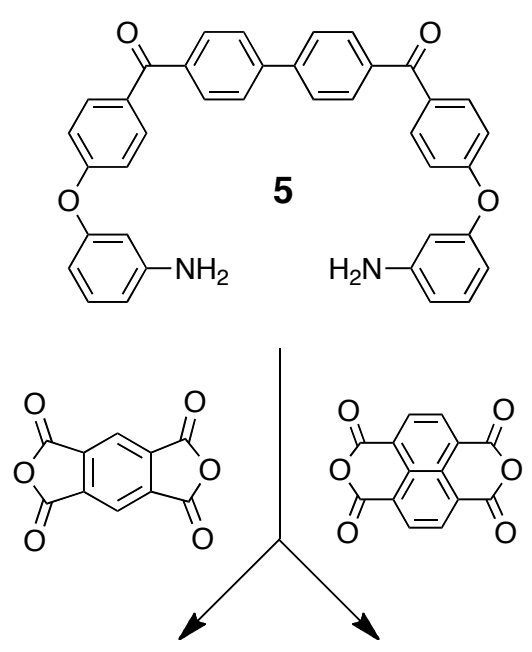

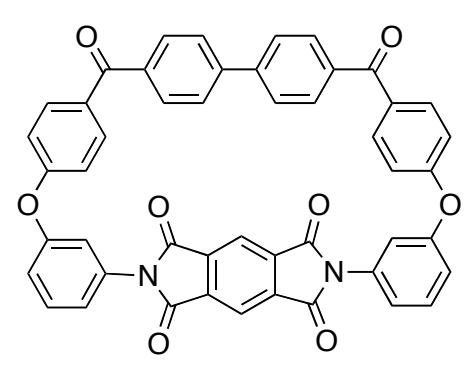

6

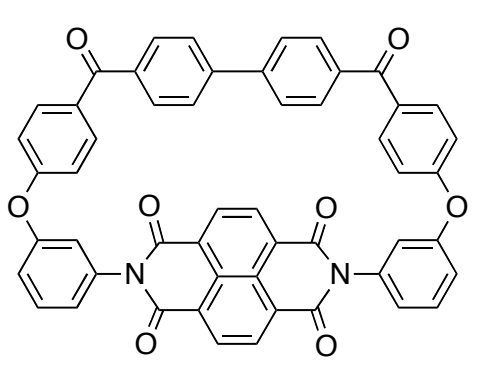

7

Scheme 1. Syntheses of the macrocyclic ether-imide-ketones 6 and 7 via cycloimidization.

Nevertheless, sufficient amounts of $\mathbf{6}$ and $\mathbf{7}$ were obtained to allow binding studies with tweezermolecules 3 and 4 . Addition of an equimolar amount of $\mathbf{3}$ to a solution of macrocycle $\mathbf{6}(4 \mathrm{mM})$ in $\mathrm{CDCl}_{3} /$ trifluoroacetic acid (6:1, v:v) resulted in a marked upfield shift (ca. $2.3 \mathrm{ppm}$ ) of the pyromellitimide ${ }^{1} \mathrm{H}$ NMR resonance. This large complexation shift arises from extensive aromatic ring- 
current shielding of the pyromellitimide protons by the pyrenyl tweezer-arms and so indicates relatively strong complexation of the two components. A charge-transfer absorption resulting from complexation is observed at $492 \mathrm{~nm}$, and this absorption was used to determine the binding constant $\left(K_{\mathrm{a}}=7500 \mathrm{M}^{-1}\right.$ in chloroform/hexafluoropropan-2-ol, 6:1 v/v) for complex [3+6] by the UV-visible dilution method. ${ }^{19}$

The corresponding binding constant for the sulfone-based macrocyclic complex $[\mathbf{3 + 1}]$, at $9,200 \mathrm{M}^{-1}{ }^{20}$ is some $20 \%$ greater than for $[\mathbf{3 + 6}]$. Since the standard error in binding constants determined by the UVvisible dilution method is only ca. $10 \%,{ }^{19}$ this result indicates that replacing the sulfone linkages in macrocycle 1 by ketone groups, as in macrocycle $\mathbf{6}$, does indeed lower the binding constant for tweezermolecule 3. Single crystal X-ray analysis of $\mathbf{6}$ provided a ready explanation for this effect since, as shown in Figure 2, both the 4,4'-biphenylene unit and the pyromellitimide residue in 6 lie essentially parallel to the mean plane of the macrocycle rather than, as in $\mathbf{1}$, perpendicular to it. ${ }^{18}$ Macrocycle $\mathbf{6}$ is thus "self-filling": in the solid state there is virtually no cavity at all.

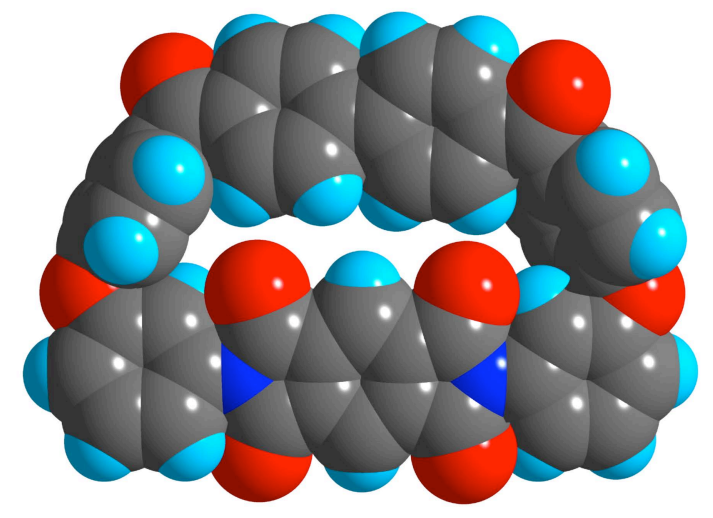

6

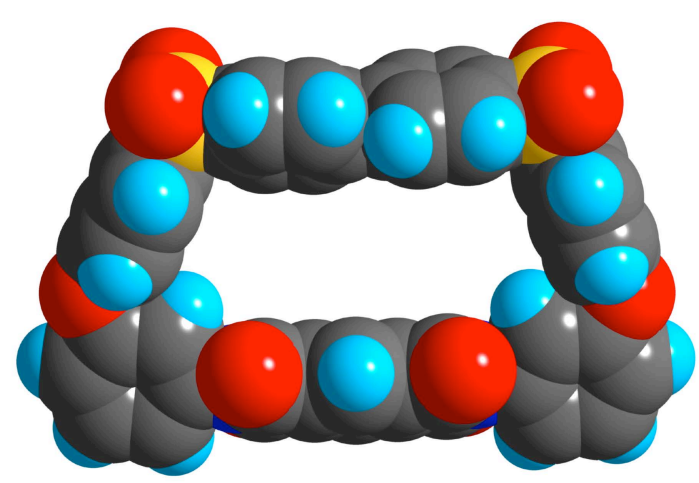

1

Figure 2. X-ray structures of macrocycles 6 and 1. The space-filling representations show that, in the solid state, the 4,4'-biphenylene and pyromellitimide residues fill the cavity of $\mathbf{6}$ almost completely, as a result of their nearparallel orientation relative to the ring-plane. In contrast, these residues lie near-perpendicular to the ring-plane in macrocycle $1 .^{17,18}$ Inter-ring torsion angles about the sulfone units in $\mathbf{1}$ are $89,77,88,80^{\circ}$ (mean $84^{\circ}$ ), and about the carbonyl groups in 6 are $61,5,41,21^{\circ}$ (mean $\left.32^{\circ}\right)$. 
However, it is clear from NMR and UV-visible absorption data that complexation between $\mathbf{3}$ or $\mathbf{4}$ and the ketone-based macrocycle $\mathbf{6}$ does occur in solution, and in fact we were able to isolate deep red crystals of a 1:1 complex between macrocycle $\mathbf{6}$ and the pyridine based tweezer-molecule 4 . These crystals were of considerably better quality than crystals of the corresponding complex with tweezermolecule 3 and so were chosen for single-crystal X-ray analysis. The X-ray structure of complex [4+6] is shown in Figure 3a, from which it is evident that the macrocycle binds to the tweezer-molecule by virtue of a ca. $90^{\circ}$ rotation of the pyromellitimide residue out of the macrocyclic plane. This rotation allows the tweezer to access both faces of the diimide, and to form two convergent hydrogen bonds (NH---O=C) from the tweezer amide groups to a pyromellitimide carbonyl oxygen. The 4,4'biphenylene residue, however, remains parallel to the macrocyclic plane and so prevents the tweezermolecule from fully accessing the cavity. This macrocycle-geometry greatly restricts the degree of complementary $\pi-\pi$-overlap achievable between host and guest. The structure of [4+6] should be contrasted with that of complex $[3+2],{ }^{20}$ where one of the tweezer-arms is able to slide past the $4,4^{\prime}-$ biphenylene residue into the macrocyclic cavity and so achieve a high degree of $\pi$ - $\pi$-overlap with the diimide unit (Figure 3b). Moreover, in complex in [3+2], the contraction of the macrocycle on binding, ${ }^{17,18}$ indicates that $\pi$ - $\pi$-stacking interactions between the 4,4'-biphenylene-disulfone and pyrenyl units must be attractive, and these interactions are clearly absent in [4+6]. Replacing the sulfone linkages with ketone groups in this system thus leads to two conformational effects on tweezer binding: (a) blocking access to the pyromellitimide unit and (b) the loss of $\pi$ - $\pi$-stacking between a tweezer-arm and a 4,4'-biphenylene unit. This analysis suggested that tweezer-molecules such as $\mathbf{3}$ and $\mathbf{4}$ should be able to distinguish between the different imide-centered triplet sequences present in copolyimides with ether-ketone and/or ether-sulfone groups flanking the diimide residues: the anticipated reduction in binding constant for ketone-containing triplets should enable a degree of sequence-selectivity to be achieved through preferential binding of the tweezer to sulfone-containing sequences. 
The appropriate polyimides were therefore synthesised by polycondensation of pyromellitic dianhydride

with diamines $\mathbf{5}$ and $\mathbf{8}$, both separately and as a 1:1 mixture (Scheme 2), affording homopolymers $\mathbf{9}$ and 10 and copolymer 11. The latter contains equal numbers of ketone and sulfone linkages distributed randomly within the polyimide chain, as indicated by the 1:2:1 ratio of integrated ${ }^{1} \mathrm{H}$ NMR intensities for resonances associated with the sequences KIK, KIS/SIK and SIS (Figure 4).

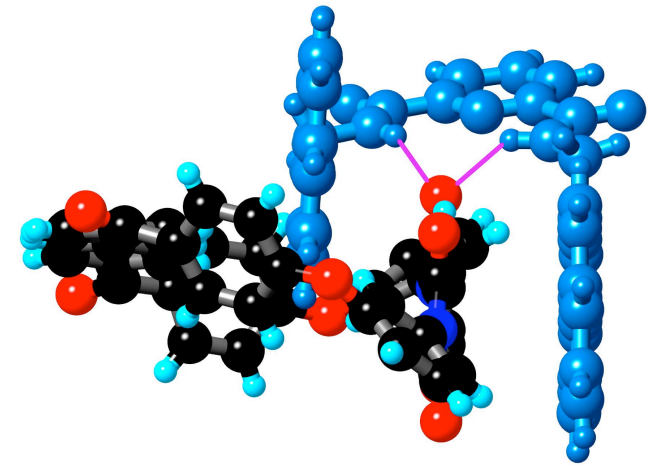

(a)

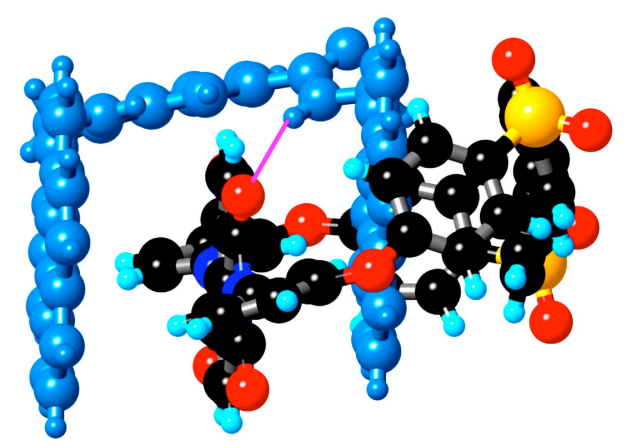

(b)

Figure 3. X-ray structures of 1:1 macrocycle-tweezer complexes: (a) [4+6] (this work) and (b) $[3+2] .{ }^{20}$ Tweezermolecules are shown in blue and hydrogen bonds (for [4+6): NH----OC $=2.22,2.26 \AA$ and $\mathrm{N}-\mathrm{H}-\mathrm{O}=151,156^{\circ}$ ) in magenta. In $[\mathbf{4 + 6}]$ the aromatic carbon atoms of the outer pyrenyl unit lie, on average, some $3.35 \AA$ from the mean plane of the pyromellitimide unit, compared with $3.24 \AA$ for the carbons of the inner pyrenyl group. However, there is only limited geometric overlap between the "inner" pyrene and the pyromellitimide residue in [4+6], owing to the 4,4'-biphenylene residue restricting tweezer access to the macrocyclic cavity (see also SI).

Addition of tweezer-molecule $\mathbf{3}$ to solutions of homopolymers $\mathbf{9}$ and $\mathbf{1 0}$ resulted in large (>1 ppm) upfield complexation shifts $(\Delta \delta)$ for the corresponding pyromellitimide resonances in the ${ }^{1} \mathrm{H}$ NMR spectrum (see SI). There was, however, a significantly greater complexation shift $(\Delta \delta=1.50 \mathrm{ppm}$ at an equimolar ratio of tweezer to diimide units) for the sulfone-based polymer $\mathbf{1 0}$ than for its ketoneanalogue $9(\Delta \delta=1.35 \mathrm{ppm}$ at the same mole ratio). This reflects a significantly higher binding constant for tweezer 3 with polymer $10\left(8,600 \mathrm{M}^{-1}\right)^{7}$ than with polymer 9 in the same solvent $\left(6,500 \mathrm{M}^{-1}\right.$ in $6: 1$ $\mathrm{CHCl}_{3}$ /hexafluoropropan-2-ol; this work - see SI). Thus the idea that, for conformational reasons, 
ketone-based units flanking the central diimide residue might destabilize tweezer-binding relative to sulfone-based sequences, was fully confirmed. Since ${ }^{1} \mathrm{H}$ NMR resonances assignable to bound and unbound sequences are not observed, it is evident that, as in other systems of this type, ${ }^{7,11,12}$ tweezerexchange must be rapid on the NMR timescale. A further key observation is that a doublet resonance for the ketone-based homopolymer 9 assigned to the protons ortho to the biphenyl linkage shows no complexation shift whatever, indicating that the biphenylene units in 9 play no part in tweezer-binding. In contrast, the same biphenylene resonance in the analogous, sulfone-based homopolymer $\mathbf{1 0}$ showed a substantial upfield complexation shift $(1.36 \mathrm{ppm})$ under analogous conditions. ${ }^{7}$ This earlier result provided evidence (confirmed both computationally and crystallographically) ${ }^{21}$ that chain-folding in $\mathbf{1 0}$ brings the 4,4'-biphenylenedisulfone groups within $\pi$ - $\pi$-stacking distance of the pyrenyl tweezer-arms, so providing additional contributions to tweezer-binding.

In the present work, NMR observations for copolymer 11 were fully consistent with those for the individual homopolymers 9 and 10. Thus, as shown in Figure 4, the three pyromellitimide resonances (at $8.4-8.5 \mathrm{ppm}$ ) assigned to triplet sequences KIK, KIS/SIK and SIS in copolymer 11 all showed upfield complexation shifts in the presence of tweezer-molecule 3 . The resonance assigned to SIS was found to shift furthest $(\Delta \delta=1.62 \mathrm{ppm}$ at equimolar 3 and pyromellitimide), KIS/SIK next furthest $(\Delta \delta=$ $1.46 \mathrm{ppm})$, and KIK showed the smallest complexation shift $(\Delta \delta=1.30 \mathrm{ppm})$. The doublet at $7.70 \mathrm{ppm}$ assigned to the protons ortho to biphenyl in the sequence "SIS" also showed a significant upfield shift, consistent with a chain-folded binding conformation. As in homopolymer $\mathbf{9}$, the corresponding doublet at $7.83 \mathrm{ppm}$, assignable to the triplet "KIK" in copolymer 11, showed no complexation shift in the presence of the tweezer (Figure 4). 
5<smiles>Nc1cccc(Oc2ccc(C(=O)c3ccc(-c4ccc(C(=O)c5ccc(Oc6cccc(N)c6)cc5)cc4)cc3)cc2)c1</smiles>

8<smiles>Nc1cccc(Oc2ccc(S(=O)(=O)c3ccc(-c4ccc(S(=O)(=O)c5ccc(Oc6cccc(N)c6)cc5)cc4)cc3)cc2)c1</smiles>

9<smiles></smiles><smiles>O=c1oc(=O)c2cc3c(=O)oc(=O)c3cc12</smiles>

10

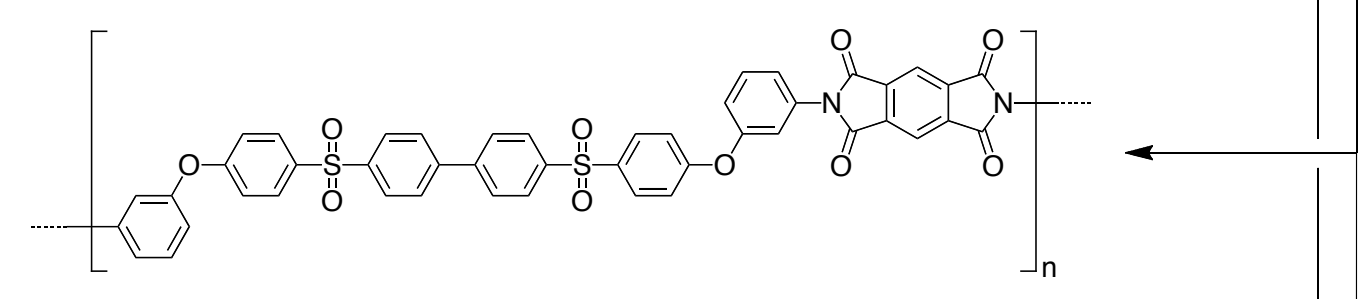

11

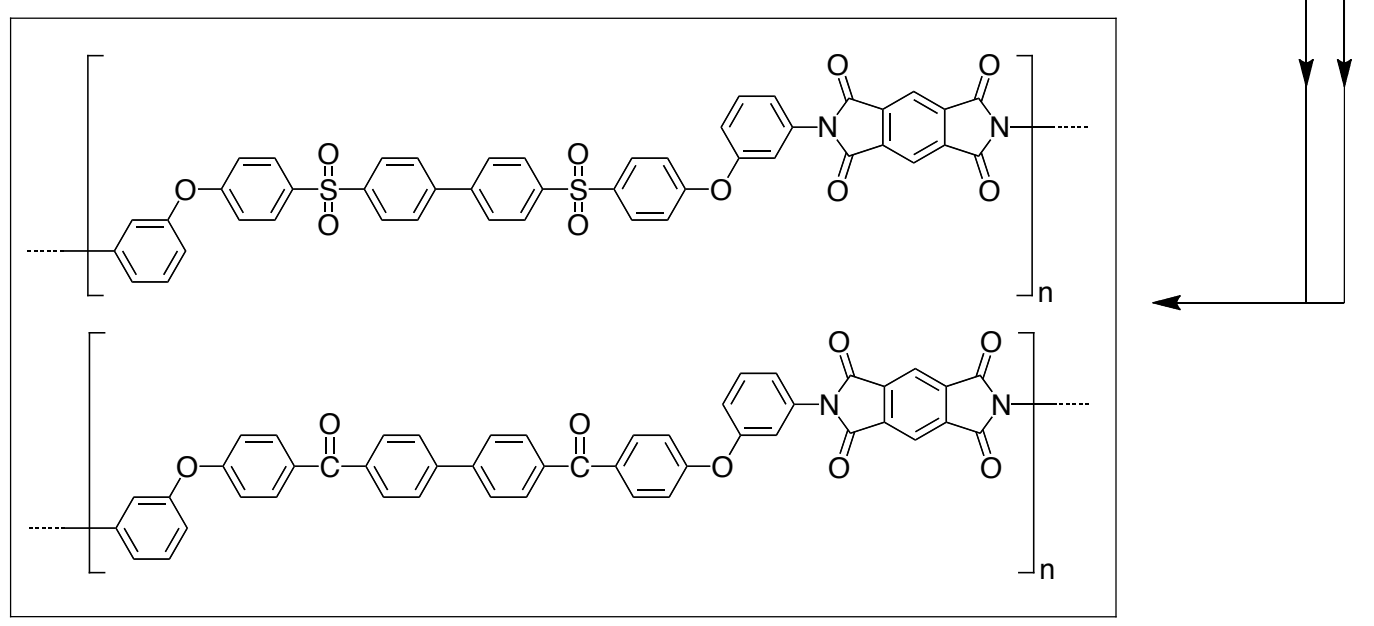

Scheme 2. Synthesis of homopolymers $\mathbf{9}$ and $\mathbf{1 0}$ and their random 1:1 copolymer $\mathbf{1 1 .}$ 


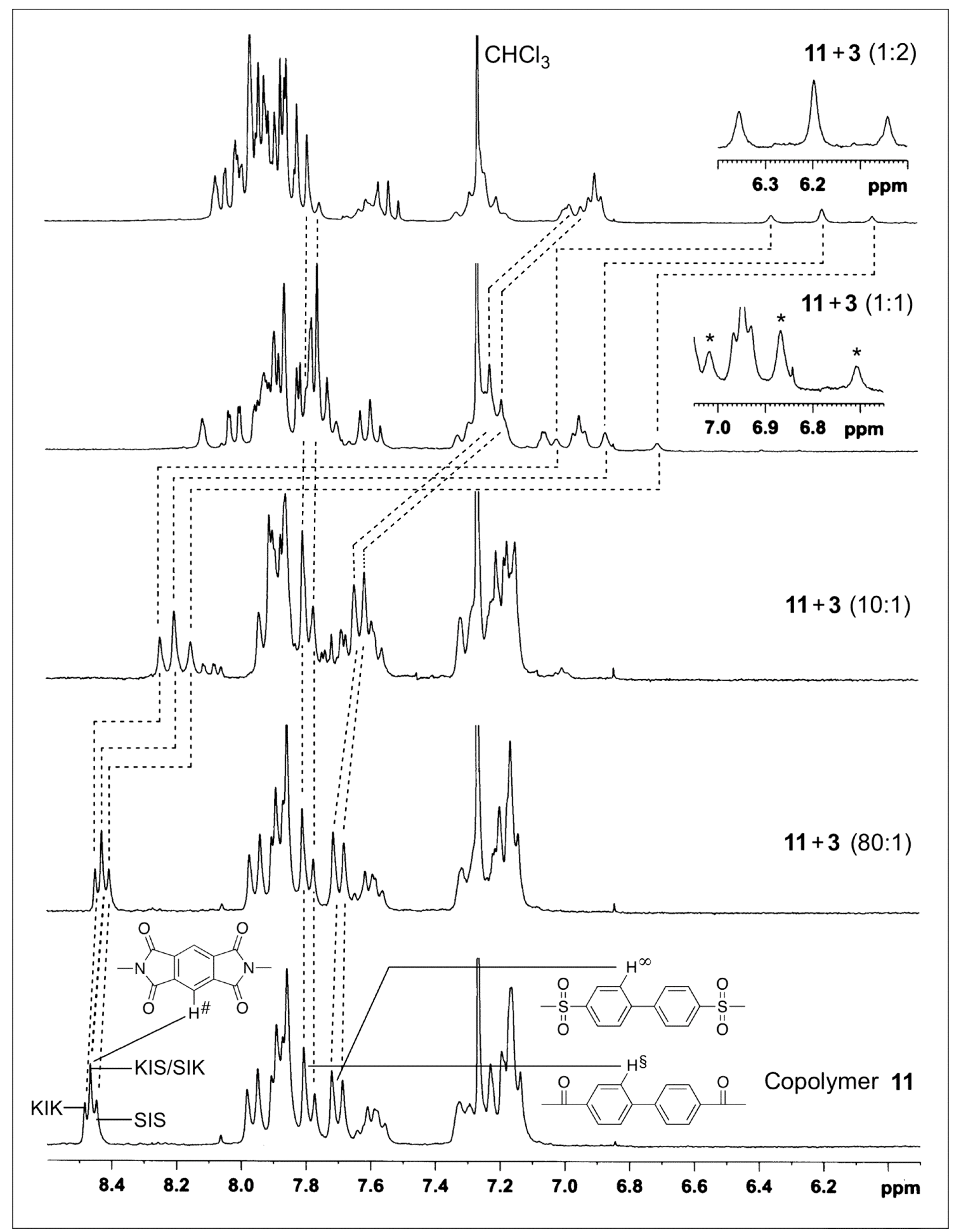

Figure 4. ${ }^{1} \mathrm{H}$ NMR titration (250 MHz, $\mathrm{CDCl}_{3} /$ hexafluoropropan-2-ol 6:1 v/v) of copolymer 11 against tweezermolecule $\mathbf{3}$, showing the large, but significantly different, upfield complexation shifts for pyromellitimide protons (\#) in the triplet sequences "SIS", KIS/SIK" and "KIK". Chain-folding at "S" is indicated by the smaller but still significant complexation shift (ca. $0.7 \mathrm{ppm}$ ) of the corresponding biphenylene resonance ( $\infty$ ), and unfolding at 'K" by the absence of such a complexation shift (§). Molar ratios represent diimide-residues:tweezer-molecules. 
Computational model-building (molecular mechanics with charge-equilibration) showed that the sequence "KIS" can adopt a low-energy chain-folded conformation analogous to that previously established for "SIS" (Figure 5a).,21 However, in the tweezer-complex with "KIS", the 4,4'biphenylenedicarbonyl residue is oriented so that (as in macrocycle complex $[\mathbf{3}+\mathbf{6}]$ ) one of the pyrenyl tweezer-arms is prevented from achieving complete $\pi$-overlap with the pyromellitimide unit (Figure 5b). In this situation, chain-folding at the " $\mathrm{K}$ " residue is evidently destabilising for tweezer-binding, and a significantly lower (ca. 10\% lower) energy-minimum was found in which the polymer chain rotates away from the tweezer to produce an "unfolded" chain conformation so that tweezer-overlap with the diimide unit can once again be maximized. Finally, an analogous computational result was found for tweezer-binding to the all-ketone homopolymer 9, which leads to a completely unfolded chain conformation at "KIK" (Figure 5c). This analysis is based on the application of a simple molecular mechanics force-field (Dreiding II) ${ }^{22}$ that includes electrostatic terms arising from charge-equilibration across all molecules in the system. Although this methodology incorporates no high-level calculations and is essentially a computational analogue of model-building, ${ }^{23}$ we have found it to be a surprisingly robust method for identifying low-energy structures in supramolecular systems based on complementary $\pi$ - $\pi$-stacking and hydrogen bonding. ${ }^{12,13,17,21}$ In the present work, the conformations identified in Figures 5a and 5c are entirely consistent with the ${ }^{1} \mathrm{H}$ NMR data noted above, in which, for example, the resonance assigned to the 4,4'-biphenylenedicarbonyl protons of polymer 9 (Figure 5c) shows no complexation shift whatever in the presence of tweezer-molecule $\mathbf{3}$. 


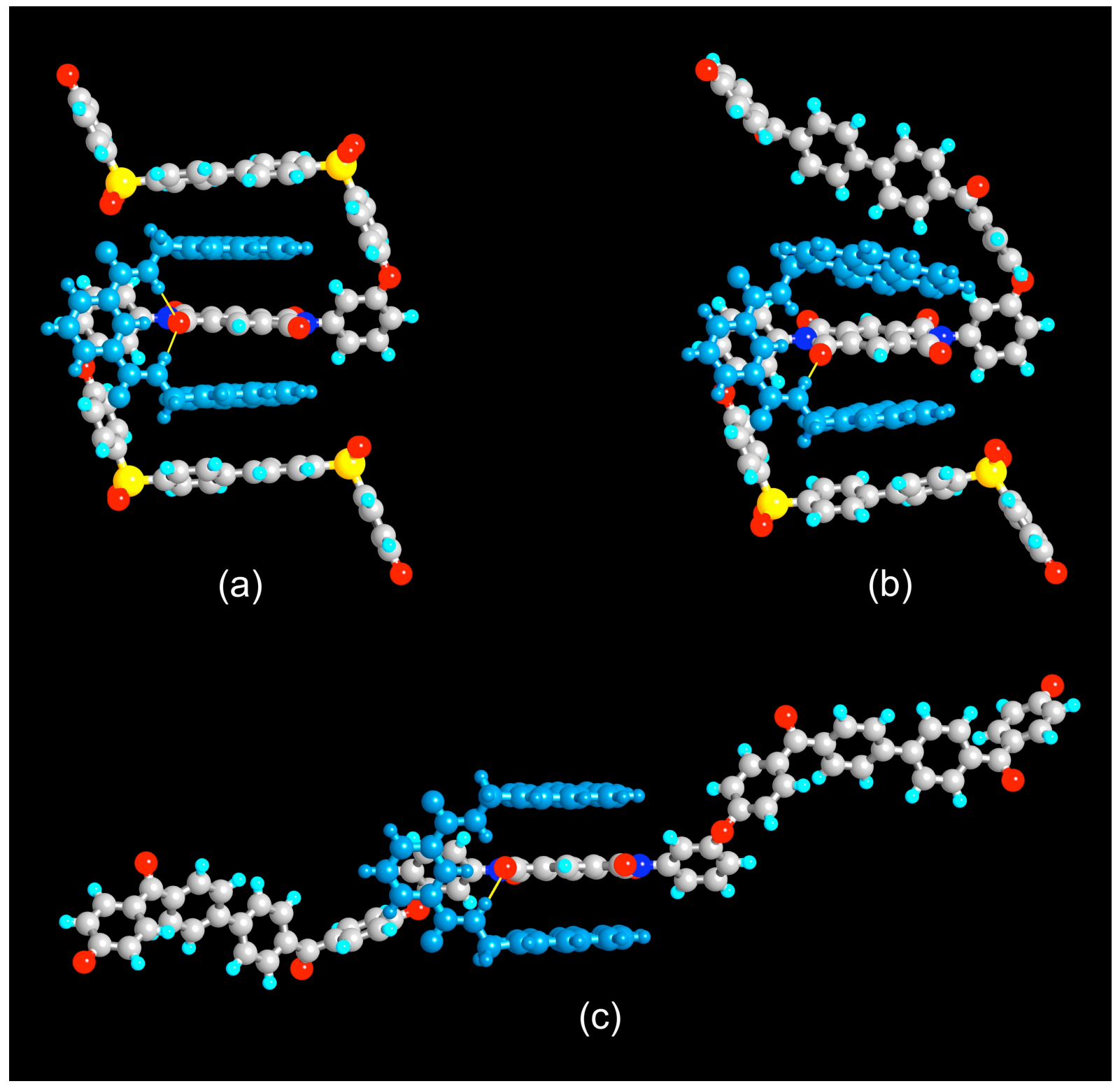

Figure 5. Local energy-minima for the binding of tweezer molecule 3 to different sequences in copolymer 11: (a) "SIS", showing a good complementary fit between the tweezer and the doubly-folded polymer chain; ${ }^{7,21}$ (b) "KIS" folded at both "S" and "K", showing that the ether-ketone residue disrupts tweezer $\pi$-stacking with the diimide residue (c.f. Figure 3a), and (c) "KIK", unfolded at both "K" residues, enabling complementary $\pi$ stacking to be re-established. The tweezer molecule is shown in blue and hydrogen bonds are indicated in yellow. A black background is used to emphasise that these images represent models, not X-ray structures. 


\section{Conclusions}

Supramolecular recognition, by tweezer-molecules, of imide-centered triplet sequences in aromatic copolyimides is modulated by the conformational preferences of adjacent monomer residues. Diaryl sulfone linkages in such residues promote chain-folding and additional tweezer-binding through $\pi-\pi-$ stacking of the pyrenyl tweezer-arms with 4,4'-biphenylenedisulfone units. Conversely, diaryl ketone linkages promote unfolding of the copolymer chain in the presence of the tweezer-molecule, to enable $\pi$ - $\pi$-overlap between the tweezer-molecule and the central diimide binding site to be maximised. As a result, tweezer-molecules bind preferentially to copolymer triplet sequences in which the central diimide units are flanked by diarylsulfone rather than diarylketone residues.

Acknowledgement. This work was supported by EPSRC under grants EP/G026203/1, EP/C533526/1 and EP/E00413X/1, and by Diamond Light Source Ltd. (a studentship to CAM).

Supporting Information Available: Full details of instrumentation and analytical techniques; synthesis and characterisation data and the ketone-based homopolymer 9; ${ }^{1} \mathrm{H}$ NMR titration data for $[\mathbf{3}+\mathbf{9}]$ and $[\mathbf{3}+\mathbf{1 0}]$; details of the binding-constant determination for the polymer complex [3+9]; full crystallographic data in CIF format for 6 and $[4+6]$. Atomic coordinates in PDB format for minimised computational models. This material is available free of charge via the Internet at http://pubs.acs.org.

1 Nirenberg, M. Trends Biochem. Sci. 2004, 29, 46-54.

2 Crick, F. H. C. Symp. Soc. Exptl. Biol. 1958, 12, 138-163.

3 (a) Rekharsky, M. V.; Yamamura, H.; Ko, Y. H.; Selvapalam, N.; Kim, K.; Inoue, Y. Chem. Commun. 2008, 2236-2238. (b) O'Hare, C. C.; Uthe, P.; Mackay, H.; Blackmon, K.; Jones, J.; Brown, T.; Nguyen, B.; Wilson, W. D.; Lee, M.; Hartley, J. A. Biochemistry 2007, 46, 11661-11670. (c) Taniguchi, Y.; Nakamura, A.; Senko, Y.; Nagatsugi, F.; Sasaki, S. J.Org. Chem. 2006, 71, $2115-$ 
2122. (d) Tanious, F.; Wilson, W. D.; Wang, L.; Kumar, A.; Boykin, D. W.; Marty, C.; Baldeyrou, B.; Bailly, C. Biochemistry 2003, 42, 13576-13586. (e) Fox, K. R.; Brown, T. Quarterly Rev. Biophys. 2005, 38, 311-320. (f) Stockley, P. G.; Stonehouse, N. J.; Murray, J. B.; Goodman, S. T. S.; Talbot, S. J.; Adams, C. J.; Liljas, L.; Valegaard, K. Nucleic Acids Res. 1995, 23, 2512-18. (g) Uil, T. G.; Haisma, H. J.; Rots, M. G. Nucleic Acids Res. 2003, 31, 6064-6078.

4 (a) Gong, C.G.; Glass, T. E.; Gibson, H. W. Macromolecules, 1998, 31, 308-313. (b) Choi, S.; Lee, J.W.; Ko, Y. H.; Kim, K. Macromolecules, 2002, 35, 3526-3531. (c) Tuncel, D.; Steinke, J. H. G. Macromolecules, 2004, 27, 288-302. (d) Owen, G. J.; Hodge, P. Chem. Commun., 1997, 11-12. (e) Hodge, P.; Monvisade, P.; Owen, G. J.; Heatley F.; Pang, Y. New. J. Chem., 2000, 24, 703-709.

5 Burd, C.; Weck, M. Macromolecules 2005, 38, 7225-7230.

6 Weck, M. Polym. Int. 2006, 56, 453- 460.

7 Colquhoun, H. M.; Zhu, Z. Angew. Chem., Int. Ed. 2004, 43, 5040-5045.

8 (a) Harmata, M. Acc. Chem. Res. 2004, 37, 862-873. (b) Klärner, F-G.; Kahlert, B. Acc. Chem. Res. 2003, 36, 919-932. (c) Chen, C. W.; Whitlock, H. W. J. Am. Chem. Soc. 1978, 100, 4921-4922. (d) Zimmerman, S. C.; VanZyl, C. M. J. Am. Chem. Soc. 1987, 109, 7894-7896. (e) Kurebayashi, H.; Haino, T.; Usui, S.; Fukazawa, Y. Tetrahedron, 2001, 57, 8667-8674. (f) Balzani, V.; Bandmann, H.; Ceroni, P.; Giansante, C.; Hahn, U.; Klärner, F-G.; Müller, U.; Müller, W. M.; Verhaelen, C.; Vicinelli, V.; Vögtle, F. J. Am. Chem. Soc. 2006, 128, 637-648. (g) Schaller, T.; Buechele, U. P.; Klärner, F-G.; Bläser, D.; Boese, R.; Brown, S. P.; Spiess, H. W.; Koziol, F.; Kussmann, J.; Ochsenfeld, C. J. Am. Chem. Soc. 2007, 129, 1293-1303. (h) Peng, X-X.; Lu, H-Y.; Han, T.; Chen, C.-F. Org. Lett. 2007, 9, 895-898.(i) Huang, H.; Drueckhammer, D. G. Chem. Commun. 2006, $2995-$ 2997. (j) Potluri, V. K.; Maitra, U. J. Org. Chem. 2000, 65, 7764-7769. (k) D’Souza, L. J.; Maitra, U. J. Org. Chem. 1996, 61, 9494-9502. (1) Goshe, A. J.; Crowley, J. D.; Bosnich, B. Helv. Chim. Acta 2001, 84, 2971- 2985. (m) Goshe, A. J.; Steele, I. M.; Ceccarelli, C.; Rheingold, A. L.; Bosnich, B. Proc. Natl. Acad. Sci. U.S.A. 2002, 99, 4823-4829. (n) Krebs, F. C.; Jørgensen, M. J. Org. Chem. 2001, 66, 6169. (o) Petitjean, A.; Khoury, R. G.; Kyritsakas, N.; Lehn. J-M. J. Am. Chem. Soc. 2004, $126,6637-6647$.

9 (a) Zhang, W.; Dichtel, W. R.; Stieg, A. Z.; Benitez, D.; Gimzewski, J. K.; Heath, J. R.; Stoddart, J. F. Proc. Natl. Acad. Sci. USA 2008, 105, 6514-6519. (b) Kang, S.; Vignon, S. A.; Tseng, H.-R.; Stoddart, J. F. Chem. Eur. J. 2004, 10, 2555-2564. (c) Vignon, S. A.; Jorrosson, T.; Iijima, T.; Tseng, H-R.; Sanders, J. K. M.; Stoddart, J. F. J. Am. Chem. Soc. 2004, 126, 9884-9885. (d) Kaiser, G.; 
Jarrosson, T.; Otto, S.; Ng, Y-F.; Bond, A. D.; Sanders, J. K. M. Angew. Chem. Int. Ed. 2004, 43, 1959-1962. (e) Zhou, Q-Z.; Jiang, X-K.; Shao, X-B.; Chen, G-J.; Jia, M-X.; Li, Z-T. Org. Lett. 2003, 5, 1955-1958. (f) Zhao, X.; Jia, M-X.; Jiang, X-K.; Wu, L-Z.; Li, Z-T.; Chen, G-J. J. Org. Chem. 2004, 69, 270-279. (g) Gabriel, G. J.; Sorey, S.; Iverson, B. L. J. Am. Chem. Soc. 2005, 127, $2637-$ 2640. (h) Reczek, J. J.; Villazor, K. R.; Lynch, V.; Swager, T. M.; Iverson, B. L. J. Am. Chem. Soc. 2006, 128, 7995-8002. (i) Reczek, J. J.; Iverson, B. L. Macromolecules 2006, 39, 5601-5603. (j) Iwanga, T.; Nakamoto, R.; Yasutake, M.; Takemura, H.; Sako, K.; Shinmyozu, T. Angew. Chem., Int. Ed. 2006, 45, 3643-3647. (j) R. Foster, Organic Charge Transfer Complexes, , Academic Press, London, 1969.

10 (a) Ghosh, S.; Ramakrishnan, S. Angew. Chem., Int. Ed. 2004, 43, 3264-3268. (b) Ghosh, S.; Ramakrishnan, S. Angew. Chem., Int. Ed. 2005, 44, 5441-5447. (c) Ghosh, S.; Ramakrishnan, S. Macromolecules 2005, 38, 676-686. (c) Hill, D. J.; Mio. M. J.; Prince, R. B.; Hughes, T. S.; Moore, J. S. Chem. Rev. 2001, 101, 3893-4011. (d) Barboiu, M.; Lehn, J-M. Proc. Natl. Acad. Sci. USA 2002, 99, 5201-5206. (e) Guichard, G.; Huc, I. Chem. Commun. 2011, 47, 5933-5941. (f) Stadler, A-M.; Kyritsakas, N.; Lehn, J-M. Chem. Commun. 2004, 2024-2025.

11 Colquhoun, H. M.; Zhu, Z.; Cardin, C. J.; Gan, Y. Chem. Commun. 2004, 2650-2652.

12 Colquhoun, H. M.; Zhu, Z.; Cardin, C. J.; Gan, Y.; Drew M. G. B. J. Am. Chem. Soc. 2007, 129, 16163-16174.

13 Colquhoun, H. M.; Zhu, Z.; Cardin, C. J.; Drew, M. G. B.; Gan, Y. Faraday Discuss. 2009, 143, 205-220.

14 Kendrick, J. J. Chem. Soc., Faraday Trans. 1990, 86, 3995-4000.

15 Colquhoun, H. M.; Aldred, P. L.; Kohnke, F. H.; Herbertson, P. L.; Baxter, I.; Williams, D. J. Macromolecules, 2002, 35, 1685-1690.

16 Colquhoun, H. M.; O'Mahoney, C. A.; Williams, D. J. Polymer, 1993, 34, 218-221.

17 Colquhoun, H. M.; Williams, D. J.; Zhu, Z. J. Am. Chem. Soc. 2002, 134, 13346-13347.

18 Colquhoun, H. M.; Zhu, Z.; Williams, D. J.; Drew, M. G. B.; Cardin, C. J.; Gan, Y.; Crawford, A. G.; Marder, T. B. Chem. Eur. J. 2010, 16, 907-918. 
19 Nielsen, M. B.; Jeppesen, J. O.; Lau, J.; Lomholt, C.; Damgard, D.; Jacobsen, J. P.; Becher, J.; Stoddart, J. F. J. Org. Chem. 2001, 66, 3559-3563.

${ }^{20}$ Colquhoun, H. M.; Zhu, Z.; Williams, D. J. Org. Lett. 2003, 5, 4353-4356.

${ }^{21}$ Zhu, Z; Cardin, C. J.; Gan, Y; Colquhoun, H. M. Nature Chem. 2010, 2, 653-660.

${ }^{22}$ Mayo, S. L.; Olafson, B. D.; Goddard III, W. A. J. Phys. Chem. 1990, 94, 8897-8909.

23 The detailed theory of complementary $\pi$-stacking is still a matter of some debate. Although it has been suggested, on the basis of charge-distribution arguments, that attractive $\pi$ - $\pi$-stacking interactions should be maximised when both $\pi$-systems are electron-poor, ${ }^{24}$ the overwhelming majority of supramolecular systems that exploit $\pi$ - $\pi$-stacking are in fact complementary, i.e. they involve interactions between $\pi$-systems which would normally be considered electron-rich (typically polycyclic aromatics, or arenes containing multiple $\pi$-donor substituents) with ones considered $\pi$ electron-poor, such as diimides, polynitroarenes or quaternised $N$-heterocyclic systems. ${ }^{9}$ More recent quantum-theoretical studies suggest that, in fact, dispersion forces provide the greatest contribution "by far" to complementary $\pi$ - $\pi$-stacking ${ }^{25}$ with induction and electrostatics playing only lesser roles. Most recently, the $\pi$ - $\pi$-stacking interaction between perylene and the naphthalene tetracarboxylic diimide residue (NDI) has even been analysed in terms of orbital overlap between the LUMO of NDI ( $\pi$-acceptor) and the HOMO of pyrene $\left(\pi\right.$-donor) ${ }^{26}$ This latter interaction closely parallels that observed between pyromellitic diimide and pyrenyl residues in the present work.

${ }^{24}$ Hunter, C. A.; Sanders, J. K. M. J. Am. Chem. Soc. 1990, 112, 5525-5534.

25 Sinnokrot, M. O.; Sherrill, C. D. J. Am. Chem. Soc. 2004, 126, 7690-7697.

${ }^{26}$ Kumar, N. S. S.; Gujrati, M. D.; Wilson, J. N. Chem. Commun. 2010, 46, 5464-5466. 
Table of Contents Graphic

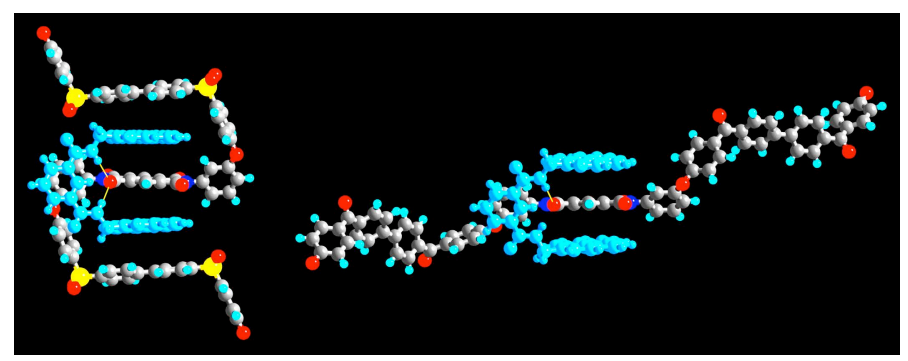

